\title{
"The best of both worlds! Continuous spinal anesthesia and peripheral nerve blocks for hip surgery in a patient with severe cardiac disease"
}

Ferreira, $\mathrm{S}^{1}$, Vieira, $\mathrm{D}^{1}$; Jesus, $\mathrm{T}^{1}$; Antunes, $\mathrm{C}^{1}$; Barros, $\mathrm{A}^{1}$; Magalhães, $\mathrm{J}^{1}$

${ }^{1}$ Anesthesiology department of Senhora da Oliveira Hospital - Guimarães

\section{BACKGROUND}

- Elderly patient with severe cardiovascular disease $\rightarrow$ Daily challenge for the anesthesiologist.

- Regional Anesthesia presents as a good and safe alternative for those patients.

\section{CASE REPORT}

- 84y man, ASA IV, severe cardiac depression (LVEF 26\%), ICD, low functional ability

- Auricular fibrillation (reverted hipocoagulation previously)

- Chronic kidney disease, diabetes mellitus, isquemic encephalopathy

$\checkmark$ PROPOSED SURGERY: LEFT HEMIARTHROPLASTY AFTER POST TRAUMATIC FRACTURE

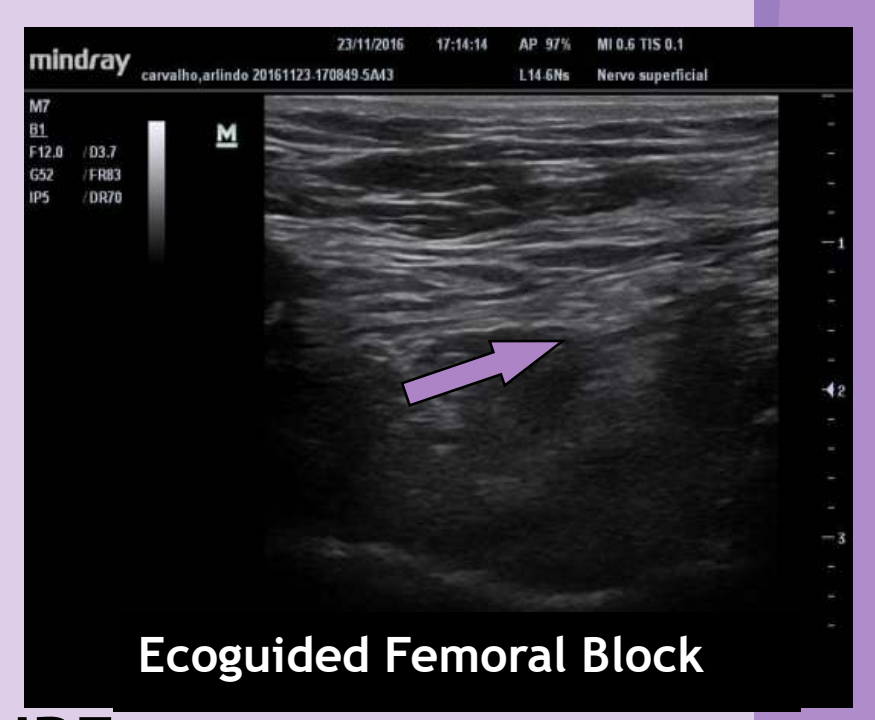

$\checkmark \quad$ ICD disabled, desfibrillation pads were placed, radial catheter for invasive blood pressure monitoring

Continuos spinal
block (with
epidural kit)
Paramedian
aproach

2 drops in MAP (< $65 \mathrm{mmHg}$ ), solved without discomfort with ephedrine $10 \mathrm{mg}$

$\checkmark \quad$ In the ICU for poor controlled pain, it was asked colaboration to perform advanced analgesia techniques

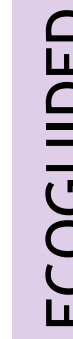

- Femoral Block

- Lateral Cutaneous Femoral Block

- Anterior branch of Obturator Nerve Block into subaracnoid space

Sufentanyl 2 ug
+
Ropivacaine
$0,33 \% 2,6 \mathrm{mg}$
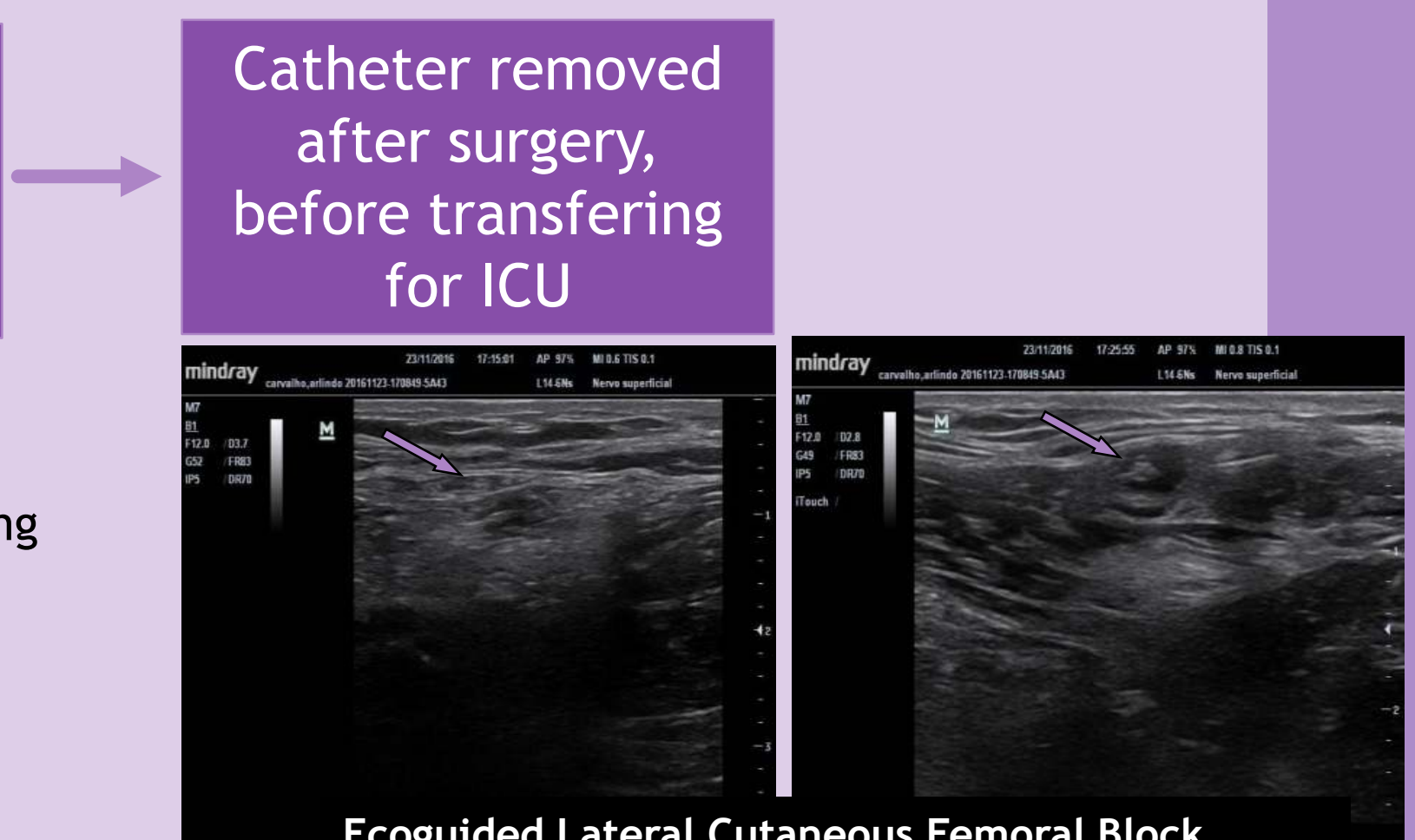

Ecoguided Lateral Cutaneous Femoral Block
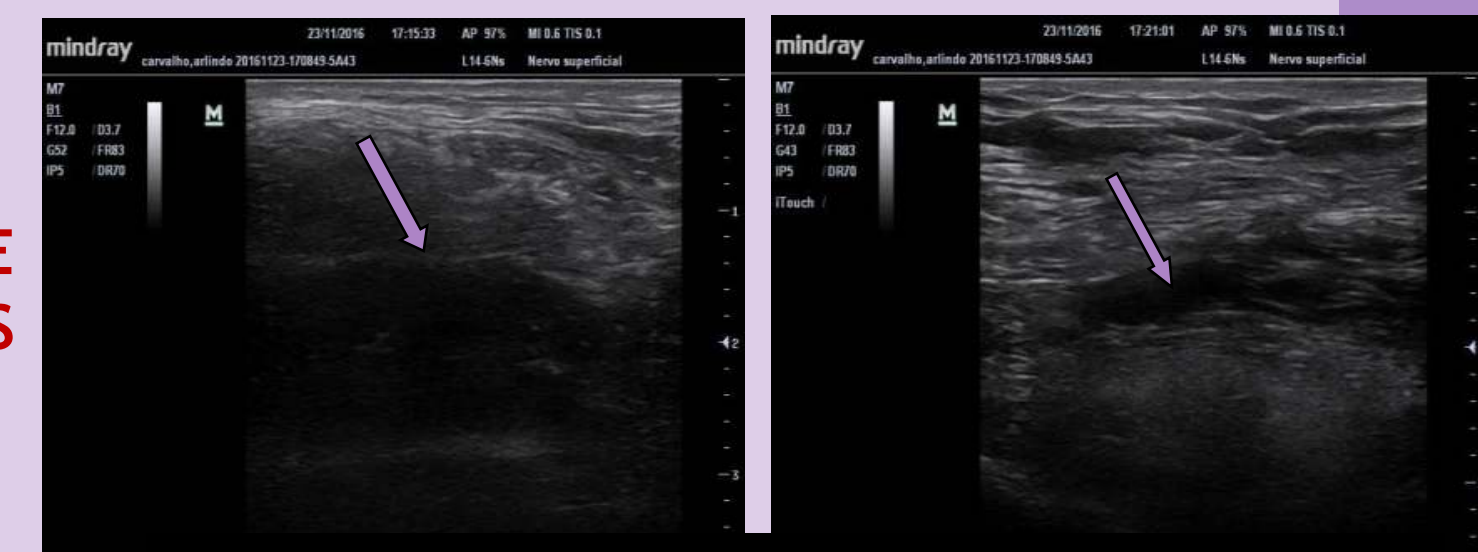

Ecoguided Anterior Branch of Obturator Nerve Block

\section{DISCUSSION}

- Continuous Spinal Block allows to titrate minimum effective doses, minimizing cardiovascular instabilitaty, specially in the elderly patient with severe CV disease.

$\checkmark$ Ultrasound guided peripheral blocks for postoperative pain control allowed a superior cardiovascular stability and patient comfort.

Advanced analgesia techniques allow minimizing opiate use avoiding opiates' undesirable side effects.

- Saber R, Metainy S. Continuous spinal anesthesia versus single small dose bupivacaine-fentanyl spinal anesthesia in high risk elderly patients: A randomized controlled trial. Egyptian Journal of Anaesthesia (2015) $31,233-238$

Jiménez MIS, Gago MB, et al. Efficacy of obturator and femoral cutaneous nerve blocks for postoperative analgesia in hip surgery. Rev. Esp. Anestesiol. Reanim. 2009; $56: 590-597$ 